\title{
ESTOQUES DE CARBONO NO SOLO E NA BIOMASSA EM PLANTAÇÕES DE EUCALIPTO(1)
}

\author{
Alcides Gatto ${ }^{(2)}$, Nairam Félix de Barros $^{(3)}$, Roberto Ferreira \\ Novais $^{(3)}$, Ivo Ribeiro da Silva ${ }^{(3)}$, Hélio Garcia Leite ${ }^{(4)}$, Fernando \\ Palha Leite $^{(5)}$ \& Ecila Maria de Albuquerque Villani ${ }^{(6)}$
}

\begin{abstract}
RESUMO
O eucalipto é a principal espécie florestal plantada no Brasil. Todavia, são escassas informações acerca do $\mathrm{C}$ estocado no solo e na biomassa desses plantios. Este trabalho teve como objetivos avaliar o estoque de C no solo (ECS) em plantações de eucalipto e determinar quais características edafoclimáticas determinam esse estoque. $O$ estudo foi conduzido em eucalipto cultivado na região centro-leste do Estado de Minas Gerais, abrangendo cinco regiões: Cocais (CO), Rio Doce (RD), Sabinópolis (SA), Santa Bárbara (SB) e Virginópolis (VI). Foi calculado o estoque de $\mathrm{C}$ no solo até $100 \mathrm{~cm}$ de profundidade em plantações de eucalipto em áreas com predomínio de seis classes de solo: Cambissolo Háplico (CX), Latossolo Amarelo (LA), Latossolo Vermelho (LV), Latossolo Vermelho-Amarelo (LVA), Neossolo Flúvico (RU) e Plintossolo Pétrico (FF). Os estoques de C no solo variaram entre regiões e classes de solo. O maior ECS ocorreu no $\mathrm{LV}$, com $183,07 \mathrm{t} \mathrm{ha}^{-1}$ de $\mathrm{C}$, seguido pelas classes de CX, LVA, LA, FF e RU, com 135,65, 130,95, 121,58, 112,01 e $95,08 \mathrm{t} \mathrm{ha}^{-1}$ de $\mathrm{C}$, respectivamente. Em relação ao estoque médio de $\mathrm{C}$ no solo por região, considerando todas as classes de solo, o maior ECS foi de 141,22 $\mathrm{tha}^{-1}$, determinado na região de VI, na profundidade até $100 \mathrm{~cm}$ de profundidade, seguida pelas regiões $\mathrm{SA}$, CO, SB e RD, com 135,54, 127,26, 112,89 e 80,79 t ha he $^{-1}$, respectivamente. Ao se considerar o estoque de $\mathrm{C}$ total no sistema solo-planta, aos 84 meses de idade, a região de SA foi a que apresentou maior estoque, com $251,61 \mathrm{t} \mathrm{ha}^{-1}$, e a região de $\mathrm{RD}$, o menor estoque, com $186,84 \mathrm{tha}^{-1}$ de $\mathrm{C}$. O ECS pode ser estimado por equações compostas por características edofoclimáticas, sendo a variação em ECS explicada por características como teor de argila e de $\mathrm{Al}^{3+}$, pela altitude e pelo déficit hídrico da região.
\end{abstract}

Termos de indexação: características edafoclimáticas, matéria orgânica, equações alométricas, solo florestal, sequestro de carbono.

\footnotetext{
(1) Parte da Tese de Doutorado do primeiro autor apresentada ao Programa de Pós-Graduação em Solos e Nutrição de Plantas, Universidade Federal de Viçosa - UFV. Recebido para publicação em outubro de 2008 e aprovado em abril de 2010.

(2) Técnico do Ministério do Meio Ambiente, Brasília (DF). E-mail: alcidesgatto@yahoo.com.br

(3) Professores do Departamento de Solos, UFV. Bolsista do CNPq. Email: nfbarros@ufv.br, rfnovais@ufv.br; ivosilva@ufv.br

(4) Professor do Departamento de Engenharia Florestal, UFV. E-mail: hgleite@ufv.br

(5) Pesquisador da CENIBRA. E-mail: fernando.leite@cenibra.com.br

(6) Pós-Doutoranda do Departamento de Solos, UFV. Bolsista da FAPEMIG. Email: ecilavillani@yahoo.com.br
} 


\title{
SUMMARY: CARBON STORAGE IN THE SOIL AND IN THE BIOMASS OF EUCALYPT PLANTATIONS
}

\begin{abstract}
Eucalypt is the main commercial forest species in Brazil, but very little information is available in the literature on the amount of carbon stored in the soil and in the biomass of these forest stands. The main objective of this study was to estimate the amount of soil-stored carbon (SSC) of eucalypt plantations and determine soil and climate characteristics that influence SSC. The study was carried out in the Central-Eastern region of Minas Gerais State, Brazil, in five micro-regions (CO, RD, SB, SA, and VI) with varying soil and climatic conditions. Soil carbon was determined to a depth of $100 \mathrm{~cm}$. Carbon in the forest floor was estimated by allometric equations. The carbon stored in the soil-plant system differed among micro-regions and soil classes. SSC ranged from $183.1 \mathrm{t} \mathrm{ha^{-1 }}$ in Red Latosol to $95.1 \mathrm{t} \mathrm{ha} \mathrm{a}^{-1}$ in Inceptisol, and was negatively correlated to soil $\mathrm{K}, \mathrm{Ca}^{2+}$, and $\mathrm{Mg}^{2+}$ content and density in the top soil layer. SSC was highest in the micro-region VI (141.2 $t \mathrm{ha}^{-1}$, average value for all soil types) and lowest in $R D\left(80.8 t \mathrm{ha}^{-1}\right)$. Considering the soil-plant ecosystem and the usual rotation age (84 months), the absolute SSC value was greatest in the micro-region SA (251.6 tha $\left.{ }^{-1}\right)$ and lowest in $R D\left(186.8 t^{h a^{-1}}\right)$. Regression equations showed that the clay and aluminum content and altitude and water stress explained most of the SSC variation.
\end{abstract}

Index terms: soil-climate characteristics, soil organic matter, allometric equations, forest soil, carbon sequestration.

\section{INTRODUÇÃO}

É consenso mundial que as áreas florestais têm papel relevante no ciclo global de carbono (C) (IPCC, 2000). Em termos gerais, o C estocado em ecossistemas tropicais (solo e vegetação) representa cerca de 20 a $25 \%$ do $\mathrm{C}$ terrestre mundial (Cerri et al., 2001).

As plantações florestais com espécies do gênero Eucalyptus são as mais extensas no Brasil, com 3,4 milhões de hectares, correspondendo a $60,7 \%$ da área total reflorestada do País (SBS, 2006). Preconiza-se que plantações florestais de eucalipto, quando bem estabelecidas, podem fixar entre 100 e $400 \mathrm{t} \mathrm{ha}^{-1} \mathrm{de}$ $\mathrm{CO}_{2}$ durante a fase de crescimento (ECOAR, 2003).

Resultados de pesquisas têm demonstrado que solos sob florestas em regiões tropicais apresentam maior potencial de dreno de $\mathrm{C}$, comparativamente ao uso do solo para fins agrícolas, devido à maior biomassa depositada anualmente na forma de manta orgânica e de raízes mortas (Lal et al., 1995; Krishnamurthy \& Ávila, 1999).

A matéria orgânica do solo (MOS) sob plantações florestais tem grande importância no fornecimento de nutrientes às plantas, retenção de cátions, complexação de elementos tóxicos e micronutrientes, estabilidade da estrutura, infiltração e retenção de água, aeração, e na atividade microbiana, constituindose, assim, em um componente fundamental e determinante da capacidade produtiva de solos altamente intemperizados (Silva \& Mendonça, 2007).

$\mathrm{O}$ potencial de fixação e estocagem de $\mathrm{C}$ no solo sofre influência das condições climáticas locais, do relevo, da drenagem e do tipo de manejo de solo adotado, entre outras variáveis que ditam as taxas de aumento do C orgânico do solo (Lal, 2005; Falloon et al., 2007; Smith, 2008). Fonseca (1984), ao estudar o comportamento das propriedades químicas de um Latossolo Vermelho-Amarelo distrófico, sob mata de eucalipto e natural, constatou que o C orgânico do solo variou com o tipo de cobertura vegetal e decresceu exponencialmente com a profundidade do perfil do solo. Nos primeiros $10 \mathrm{~cm}$ de profundidade, o teor de $\mathrm{C}$ orgânico sob eucalipto e mata natural foi, respectivamente, de 4,5 e 5,5\%. Esse resultado pode estar relacionado ao uso anterior e ao manejo do solo sob o plantio de eucalipto, que teriam favorecido a ação dos microrganismos, reduzindo o teor inicial existente.

Madeira et al. (2002), ao avaliarem as mudanças no estoque de C em plantações de Eucalyptus globulus com 14 anos de idade, verificaram aumento no $\mathrm{C}$ estocado no solo nas áreas que receberam fertilização e irrigação, especialmente na camada de $0-20 \mathrm{~cm}$ de profundidade. Os autores atribuíram esse acréscimo à maior produção de raízes finas, o que corrobora resultados de Fabião et al. (1985) e Kätterer et al. (1995). Tchienkoua \& Zech (2004) também encontraram aumento no C estocado no solo em plantações de Eucalyptus grandis em Camarão - África, possivelmente devido à elevada relação C:N (64) da manta orgânica.

Por sua vez, Turner \& Lambert (2000), em plantações de Eucalyptus grandis com idades de 0 a 35 anos, na Austrália, verificaram decréscimo do C orgânico do solo tanto na camada superficial $(0-10 \mathrm{~cm})$ quanto em profundidade $(0-50 \mathrm{~cm})$. Segundo esses autores, essa tendência ocorreria até o completo estabelecimento da floresta, afirmando ser 
fundamental a adoção de técnicas de manejo que possibilitem maximizar o acúmulo de $\mathrm{C}$ no solo.

Zinn et al. (2002) encontraram diferenças significativas no estoque de $\mathrm{C}$ do solo (0-60 $\mathrm{cm}$ de profundidade) em plantações de Eucalyptus grandis na região de Cerrado do Estado de Minas Gerais, em decorrência da textura e da classe de solo. Em áreas de Latossolos, com $36 \%$ de argila, o estoque de $\mathrm{C}$ foi $44 \%$ maior que nas áreas de Cambissolos, com $17 \%$ de argila.

Considerando a importância do tema, são escassas as informações disponíveis em literatura a respeito dos estoques de $\mathrm{C}$ fixado no solo em plantações florestais nos trópicos. O presente trabalho teve como objetivo estimar o estoque de $\mathrm{C}$ no solo e o estoque total de $\mathrm{C}$ no sistema solo-biomassa de plantações de eucalipto na região centro-leste do Estado de Minas Gerais.

\section{MATERIAL E MÉTODOS}

\section{Caracterização geral da área}

O estudo abrangeu cinco regiões distintas quanto às características edafoclimáticas, situadas na parte centro-leste do Estado de Minas Gerais: Cocais (CO), Rio Doce (RD), Sabinópolis (SA), Santa Bárbara (SB) e Virginópolis (VI), localizadas entre as coordenadas geográficas de $18^{\circ} 38^{\prime}$ a $199^{\circ} 59^{\prime}$ de latitude sul e $42{ }^{\circ} 25^{\prime}$ ' a $43^{\circ} 20^{\prime}$ ' de longitude oeste de Greenwhich (Quadro 1).

Um dos critérios utilizados para separação das áreas de plantio por região foi a altitude de $600 \mathrm{~m}$, correspondente à isolinha de evapotranspiração potencial anual igual a $1.000 \mathrm{~mm}$, que separa a faixa megatérmica da mesotérmica. Assim, foram selecionadas áreas com altitudes superiores a $600 \mathrm{~m}$ na faixa mesotérmica, onde o clima é ameno e o relevo acidentado. Essas áreas abrangem a maior parte das regiões de $\mathrm{CO}, \mathrm{SB}$, VI e SA, enquanto as áreas da região do $\mathrm{RD}$ enquadram-se na faixa megatérmica, com relevo predominante plano a ondulado e temperaturas mais elevadas (Fabres et al., 1987).
O clima predominante nas regiões de SB, VI e SA, segundo a classificação de Köppen, é do tipo Cwa, temperado chuvoso-mesotérmico, com as chuvas ocorrendo, predominantemente, no verão e inverno, com baixas precipitações. No entanto, na região de $\mathrm{RD}$, com altitudes inferiores a $400 \mathrm{~m}$, predomina o tipo Aw, tropical, com verão chuvoso e inverno seco de maio a setembro. Na região serrana de CO, o clima é do tipo $\mathrm{Cwb}$, mesotérmico de inverno seco e verão ameno (Cenibra, 2001).

O relevo dominante é ondulado, com interflúvios normalmente estreitos levemente aplanados e encostas com pendentes longas, de forma convexa ou convexocôncava, com declividade que pode chegar a $45^{\circ}$. Diferenças de nível em casos extremos podem atingir valores de até $400 \mathrm{~m}$ entre as maiores altitudes e o fundo dos vales. A maior parte das áreas com plantios está situada entre 600 e $900 \mathrm{~m}$ de altitude. As faixas de declividade entre $0^{\circ}$ e $15^{\circ}, 16^{\circ}$ e $26^{\circ}$ e acima de $26^{\circ}$ representam 43 , 42 e $15 \%$ das áreas com plantios, respectivamente.

Neste estudo utilizaram-se informações resultantes do levantamento semidetalhado dos solos realizado nas áreas da Cenibra no período de 2000 a 2001, que abrangeu cerca de 80 mil hectares de plantações de eucalipto com idade de 84 meses (Cenibra, 2001). Foram avaliadas seis classes de solos: Cambissolo Háplico (CX), Latossolo Amarelo (LA), Latossolo Vermelho (LV), Latossolo Vermelho-Amarelo (LVA), Neossolo Flúvico (RU) e Plintossolo Pétrico (FF). Essas classes são representativas da região em estudo quanto à abrangência e à área cultivada com eucalipto, não sendo considerada a unidade de mapeamento, cujas características se encontram em Embrapa (1999). No levantamento, amostras dos perfis analisados (Quadro 2) foram coletadas nas profundidades de 0 20, 20-40, 40-60 e 60-100 cm, em trincheiras abertas nas áreas selecionadas. O material coletado foi seco e peneirado (malha de $2 \mathrm{~mm}$ ) para obtenção da terra fina seca ao ar (TFSA) e submetido às caracterizações físicas e químicas (Embrapa, 1997). Os resultados das análises foram apresentados em Gatto (2005).

\section{Quadro 1. Principais características ambientais das regiões do estudo}

\begin{tabular}{|c|c|c|c|c|c|}
\hline \multirow{2}{*}{ Característica } & \multicolumn{5}{|c|}{ Região(1) $^{(1)}$} \\
\hline & $\mathrm{CO}$ & RD & SA & SB & VI \\
\hline Latitude & $19^{\circ} 29^{\prime}$ & $19^{\circ} 16^{\prime}$ & $18^{\circ} 38^{\prime}$ & $19^{\circ} 59^{\prime}$ & $18^{\circ} 42^{\prime}$ \\
\hline Longitude & $42^{\circ} 48^{\prime}$ & $42^{\circ} 25^{\prime}$ & $42^{\circ} 56^{\prime}$ & $43^{\circ} 20^{\prime}$ & $42^{\circ} 30^{\prime}$ \\
\hline Precipitação pluvial média anual (mm) & 1.342 & 1.204 & 1.183 & 1.450 & 1.148 \\
\hline Temperatura mínima anual $\left({ }^{\circ} \mathrm{C}\right)$ & 16,6 & 18,9 & 15,9 & 17,3 & 15,3 \\
\hline Temperatura máxima anual $\left({ }^{\circ} \mathrm{C}\right)$ & 24,3 & 31,2 & 26,7 & 27,2 & 22,8 \\
\hline Temperatura média anual $\left({ }^{\circ} \mathrm{C}\right)$ & 20,0 & 24,8 & 21,7 & 22,3 & 16,8 \\
\hline Umidade relativa média anual (\%) & 77 & 65 & 63 & 62 & 79 \\
\hline Déficit hídrico anual (mm) & 105 & 300 & 203 & 195 & 198 \\
\hline Altitude média $(\mathrm{m})$ & 1.200 & 290 & 800 & 740 & 1.000 \\
\hline Produtividade média aos sete anos $\left(\mathrm{m}^{3} \mathrm{ha}^{-1}\right)$ & 241 & 197 & 224 & 203 & 248 \\
\hline
\end{tabular}

${ }^{(1)}$ CO: Cocais; RD: Rio Doce; SA: Sabinópolis; SB: Santa Bárbara; VI: Virginópolis. 


\section{Estoque de carbono no solo}

Os teores de C orgânico foram determinados (Walkley \& Black, 1934) e, posteriormente, convertidos em C total, conforme Gatto (2005). O estoque de C no solo (ECS) foi calculado por classes de solo e região, e o número de observações variou de 22 a 82 (Quadro 2). Foram quantificados os estoques de $\mathrm{C}$ orgânico dos perfis do solo, por camada, até $100 \mathrm{~cm}$ de profundidade.
No cálculo do ECS adotou-se um sistema de interpolação dos horizontes dos solos em camadas, para facilitar a interpretação e comparação dos resultados.

O ECS foi obtido pela soma dos estoques em cada camada de solo, com valores médios do teor de $\mathrm{C}$ orgânico e densidade do solo da respectiva camada em todos os perfis analisados (Quadro 3). O estoque de $\mathrm{C}$ orgânico de cada camada correspondeu ao produto do

Quadro 2. Classes e número de perfis (n) de solo analisados por região, para estimativa do estoque de carbono do solo

\begin{tabular}{|c|c|c|c|c|c|}
\hline \multirow[t]{2}{*}{ Classe de solo } & \multicolumn{5}{|c|}{$\operatorname{Região}^{(1)}$} \\
\hline & $\mathrm{CO}$ & RD & SA & SB & VI \\
\hline & & & $\mathrm{n}$ & & \\
\hline Cambissolo Háplico (CX) & 13 & 18 & 10 & 13 & 10 \\
\hline Latossolo Amarelo (LA) & 10 & 26 & 2 & 2 & 4 \\
\hline Latossolo Vermelho (LV) & 6 & 6 & 15 & 2 & 13 \\
\hline Latossolo Vermelho-Amarelo (LVA) & 17 & 14 & 4 & 3 & 9 \\
\hline Neossolo Flúvico (RU) & 1 & 17 & 1 & & 4 \\
\hline Plintossolo Pétrico (FF) & 1 & 1 & 2 & 2 & 2 \\
\hline Total & 48 & 82 & 34 & 22 & 42 \\
\hline
\end{tabular}

(1) CO: Cocais; RD: Rio Doce; AS: Sabinópolis; SB: Santa Bárbara; VI: Virginópolis.

Quadro 3. Alumínio trocável ( $\left.\mathrm{Al}^{3+}\right)$, carbono orgânico (CO), densidade do solo (DS) e teor de argila dos solos sob plantações de eucalipto aos 84 meses de idade, nas cinco regiões avaliadas

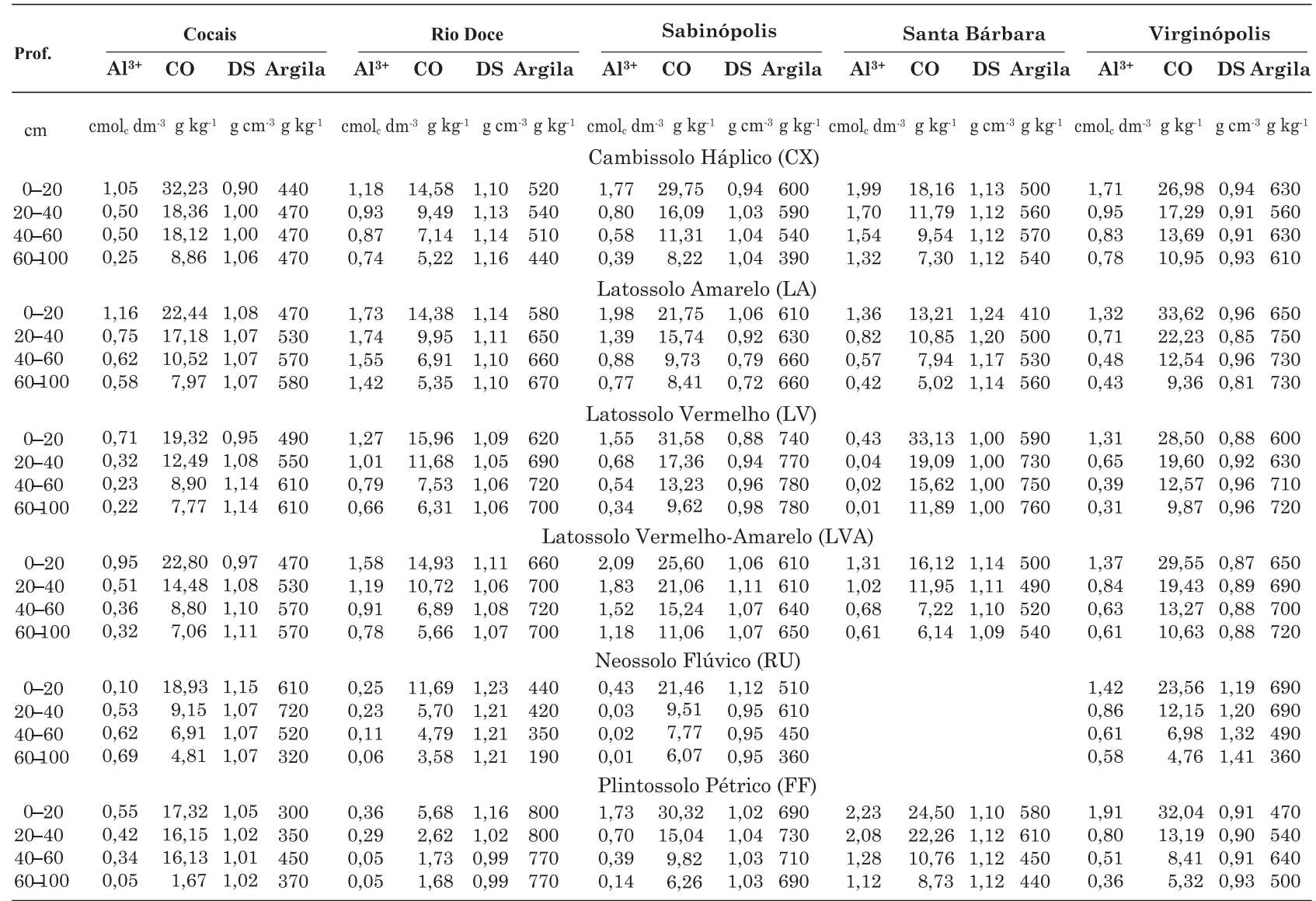

$\mathrm{Al}^{3+}\left(\mathrm{KCl} 1 \mathrm{~mol} \mathrm{~L}^{-1}\right)$; CO: carbono orgânico determinado pelo método Walkley \& Black e convertido para CHNS/O; DS: densidade do solo; Argila: método da pipeta (Embrapa, 1997). 
teor de $\mathrm{C}$ do solo $\left(\mathrm{C}, \mathrm{g} \mathrm{kg}^{-1}\right)$ pela densidade do solo (DS, $\mathrm{g} \mathrm{cm}^{-3}$ ) e pela profundidade da camada, empregandose a fórmula:

$$
\mathrm{ECS}=(\mathrm{C} \times \mathrm{DS} \times \mathrm{p}) / 10
$$

em que ECS = estoque de carbono do solo $\left(\mathrm{t} \mathrm{ha}^{-1}\right) ; \mathrm{C}=$ teor de carbono do solo $\left(\mathrm{g} \mathrm{kg}^{-1}\right)$; $\mathrm{DS}=$ densidade do solo $\left(\mathrm{g} \mathrm{cm}^{-3}\right) ; \mathrm{e} \mathrm{p}=$ profundidade da camada do solo $(\mathrm{cm})$.

\section{Estoque de carbono total no sistema solo- biomassa}

Para avaliação do estoque de carbono total (ECT) no sistema solo-biomassa de plantações de eucalipto, aos 84 meses de idade, considerou-se o C estocado no lenho, nos resíduos da colheita, na serapilheira e do C estocado no solo até $100 \mathrm{~cm}$ de profundidade. Os dados referentes ao estoque de $\mathrm{C}$ na biomassa podem ser obtidos em Gatto (2005). O ECT foi calculado pela seguinte fórmula:

$$
\mathrm{ECT}=\mathrm{ECS}+\mathrm{ECB}
$$

em que: $\mathrm{ECT}=$ estoque de carbono total $\left(\mathrm{t} \mathrm{ha}^{-1}\right)$; ECS = estoque de carbono no solo $\left(\mathrm{t} \mathrm{ha}^{-1}\right) ; \mathrm{e} \mathrm{ECB}=$ estoque de carbono na biomassa (tronco + copa + serapilheira) (t ha-1).

\section{Análise estatística}

As principais características edafoclimáticas (Gatto, 2005) foram submetidas à análise de regressão multivariada, pelo processo Stepwise, visando à seleção das características para comporem uma equação de regressão a fim de estimar o ECS para cada camada de solo e para a seção de 0 a $100 \mathrm{~cm}$ de profundidade.

$\mathrm{Na}$ análise estatística dos dados das características edafoclimáticas foi utilizado o Sistema de Análise Estatística para Windows - WinStat - versão 2.0 (Machado \& Conceição, 2003).

\section{RESULTADOS E DISCUSSÃO}

\section{Estoque de carbono no solo}

Nas cinco regiões estudadas, os maiores teores de C (Quadro 3), assim como o estoque de carbono no solo (ECS) (Quadro 4), foram detectados na camada de $0-20 \mathrm{~cm}$, decrescendo em profundidade, para todas as classes de solos. Os teores mais elevados foram dos Latossolos, principalmente nas regiões de Sabinópolis e Virginópolis.

Os resultados obtidos podem ser atribuídos, na classe dos Latossolos, ao maior teor de argila desses solos, favorecendo a formação de agregados estáveis, os quais dificultariam tanto a decomposição quanto a mineralização das frações orgânicas do solo (Hassink et al., 1997; Matus \& Maire, 2000). Outra possível justificativa para os maiores teores de C orgânico na camada superficial do solo é o aporte de material orgânico, proveniente da queda de folhas, galhos e da casca das árvores, formando a manta orgânica e a maior densidade de raízes finas, fato comum em plantações de eucalipto cultivadas em solos com baixo nível de fertilidade (Neves, 2000; Pulrolnik et al., 2009). Esse material, somado aos resíduos da colheita, em condições favoráveis de crescimento, pode representar $26 \%$ do total de matéria seca produzida em plantações de eucalipto aos sete anos de idade, conforme constatou Leite (2001). A produtividade florestal nessas duas regiões está entre as mais elevadas (Quadro 1).

Em relação às classes e ao estoque médio de $\mathrm{C}$ orgânico no solo (0-100 cm), constatou-se, em ordem decrescente, a seguinte situação: Latossolo Vermelho (LV), com 140,99 t ha-1; Cambissolo Háplico (CX), com 135,65 t ha $^{-1}$; Latossolo Vermelho-Amarelo (LVA), com $130,95 \mathrm{t} \mathrm{ha}^{-1}$; Latossolo Amarelo (LA), com 121,58 $\mathrm{t} \mathrm{ha}^{-1}$; Plintossolo Pétrico (FF), com 112,01 t ha-1; e Neossolo Flúvico (RU), com 95,08 t ha-1 de C orgânico (Quadro 4).

Dentro da classe dos Latossolos, maior valor absoluto de ECS foi verificado no LV, com 183,07 t ha-1, seguido pelo LVA, com 180,95 t ha-1, e pelo LA, com 157,05 t ha $^{-1}$, para as regiões de Santa Bárbara, Sabinópolis e Virginópolis. Considerando o C orgânico médio estocado por classe de solo, a quantidade nos Latossolos (131,17 t ha-1) se aproximou da observada na classe dos Cambissolos (135,65 t ha-1), sendo apenas $3,3 \%$ inferior. Para os RU e os FF, esses valores foram 29,9 e 17,4 \% menores que os encontrados nos CX, respectivamente.

Os maiores ECS encontrados na classe dos Latossolos podem estar relacionados às características desses solos. Em geral, eles são profundos e bem drenados, praticamente sem impedimentos ao crescimento do sistema radicular do eucalipto, o que influenciaria positivamente a distribuição e a manutenção de C orgânico no solo. Os Latossolos apresentam, em média, maior teor de argila que as demais classes, com valores médios acima de $60 \%$ e alto grau de floculação de argila, características que conferem maior proteção física ao C orgânico, devido à formação de complexos argilo-orgânicos, menos propensos à decomposição. Além da argila, os sesquióxidos de $\mathrm{Fe}$ e $\mathrm{Al}$ também influenciam a estabilização da MOS em muitos solos de clima tropical, como os Latossolos, exercendo proteção física aos compostos orgânicos, causando perda de solubilidade e envolvendo estes compostos em Fe insolúvel ou hidróxidos de Al (Mikutta et al., 2006; Kögel-Knabner et al., 2008).

Somado às características mencionadas, os LVs ocorrem preferencialmente nos topos aplainados mais expressivos do relevo ondulado e forte ondulado ou nas encostas com declives mais acentuados (Cenibra, 2001, 2005). Nessa condição, em altitude média superior a 
Quadro 4. Estoque de carbono no solo (ECS), por região, classes e profundidades, sob plantações de eucalipto, aos 84 meses de idade

\begin{tabular}{|c|c|c|c|c|c|c|c|}
\hline \multirow{2}{*}{ Profundidade } & \multicolumn{5}{|c|}{$\operatorname{Região}^{(1)}$} & \multirow{2}{*}{ Média } & \multirow{2}{*}{$\mathbf{s}$} \\
\hline & $\mathrm{CO}$ & RD & SA & SB & VI & & \\
\hline \multirow[t]{2}{*}{$\mathrm{cm}$} & \multicolumn{5}{|c|}{$-\operatorname{ECS}\left(t h a^{-1}\right)$} & & \\
\hline & \multicolumn{5}{|c|}{ Cambissolo Háplico (CX) } & & \\
\hline $0-20$ & 57,72 & 32,18 & 56,06 & 41,00 & 50,59 & 47,51 & 10,8 \\
\hline $20-40$ & 36,86 & 21,46 & 33,22 & 26,32 & 31,42 & 29,86 & 6,0 \\
\hline $40-60$ & 36,38 & 16,22 & 23,48 & 21,28 & 24,94 & 24,46 & 7,4 \\
\hline $60-100$ & 37,44 & 24,11 & 34,19 & 32,55 & 40,84 & 33,82 & 6,3 \\
\hline Total & 168,40 & 93,96 & 146,94 & 121,15 & 147,80 & 135,65 & 28,7 \\
\hline \multicolumn{8}{|c|}{ Latossolo Amarelo (LA) } \\
\hline $0-20$ & 48,62 & 32,72 & 46,28 & 32,70 & 64,78 & 45,02 & 13,3 \\
\hline $20-40$ & 36,88 & 22,14 & 29,08 & 26,10 & 37,83 & 30,41 & 6,8 \\
\hline $40-60$ & 22,45 & 15,22 & 15,42 & 18,64 & 24,03 & 19,15 & 4,0 \\
\hline $60-100$ & 34,05 & 23,46 & 24,11 & 23,00 & 30,41 & 27,00 & 5,0 \\
\hline Total & 142,00 & 93,53 & 114,89 & 100,43 & 157,05 & 121,58 & 27,2 \\
\hline \multicolumn{8}{|c|}{ Latossolo Vermelho (LV) } \\
\hline $0-20$ & 36,88 & 34,75 & 55,79 & 66,12 & 50,41 & 48,79 & 13,1 \\
\hline $20-40$ & 26,94 & 24,63 & 32,69 & 38,15 & 36,18 & 31,72 & 5,8 \\
\hline $40-60$ & 20,29 & 15,93 & 25,41 & 31,27 & 24,02 & 23,38 & 5,7 \\
\hline $60-100$ & 35,53 & 26,87 & 37,60 & 47,53 & 37,94 & 37,09 & 7,4 \\
\hline Total & 119,63 & 102,18 & 151,50 & 183,07 & 148,55 & 140,99 & 31,2 \\
\hline \multicolumn{8}{|c|}{ Latossolo Vermelho-Amarelo (LVA) } \\
\hline $0-20$ & 44,25 & 33,07 & 54,20 & 36,65 & 51,61 & 43,95 & 9,2 \\
\hline $20-40$ & 31,25 & 22,84 & 46,95 & 26,51 & 34,40 & 32,39 & 9,3 \\
\hline $40-60$ & 19,40 & 14,84 & 32,62 & 15,85 & 23,35 & 21,21 & 7,2 \\
\hline $60-100$ & 31,24 & 24,35 & 47,18 & 26,88 & 37,29 & 33,39 & 9,1 \\
\hline Total & 126,14 & 95,10 & 180,95 & 105,89 & 146,66 & 130,95 & 34,2 \\
\hline \multicolumn{8}{|c|}{ Neossolo Flúvico (RU) } \\
\hline $0-20$ & 43,60 & 28,69 & 48,11 & - & 55,97 & 44,09 & 11,5 \\
\hline $20-40$ & 19,63 & 13,77 & 13,05 & - & 29,08 & 18,88 & 7,4 \\
\hline $40-60$ & 14,82 & 11,60 & 7,35 & - & 18,38 & 13,04 & 4,7 \\
\hline $60-100$ & 20,66 & 17,34 & 11,49 & - & 26,77 & 19,07 & 6,4 \\
\hline Total & 98,72 & 71,40 & 80,01 & - & 130,20 & 95,08 & 26,0 \\
\hline \multicolumn{8}{|c|}{ Plintossolo Pétrico (FF) } \\
\hline $0-20$ & 36,25 & 13,14 & 61,62 & 54,02 & 58,28 & 44,66 & 20,2 \\
\hline $20-40$ & 32,89 & 5,37 & 31,14 & 49,65 & 23,72 & 28,55 & 16,1 \\
\hline $40-60$ & 32,67 & 3,42 & 20,31 & 24,06 & 15,26 & 19,14 & 10,8 \\
\hline $60-100$ & 6,87 & 6,66 & 25,87 & 39,06 & 19,81 & 19,65 & 13,7 \\
\hline Total & 108,68 & 28,59 & 138,95 & 166,78 & 117,06 & 112,01 & 51,8 \\
\hline Média & 127,26 & 80,79 & 135,54 & 112,89 & 141,22 & 122,71 & \\
\hline
\end{tabular}

(1) CO: Cocais; RD: Rio Doce; SA: Sabinópolis; SB: Santa Bárbara; VI: Virginópolis; s: desvio-padrão.

600 m, o clima é ameno, com temperatura média anual e déficit hídrico mais baixos, quando comparado àquele da região de relevo mais plano e de altitude inferior, como na região do $\mathrm{RD}$, resultando em menores taxas de decomposição e mineralização da MOS.

Nas áreas de Neossolos Flúvicos (RU) e Plintossolos Pétricos (FF) encontram-se os menores ECS (Quadro 4). Resultados semelhantes foram obtidos por Menezes (2005), ao avaliar a produtividade da cultura do eucalipto em áreas com RU e FF, nas regiões de Rio Doce e Virginópolis. Esses resultados podem ser decorrentes do fato de esses solos serem relativamente jovens, com características morfológicas pouco definidas. Ambos caracterizam-se por apresentar ampla variabilidade quanto às características morfológicas, químicas e físicas, como: pouco profundos ou com pequena expressão dos processos pedogenéticos, tendo como consequência modificações pouco expressivas no material de origem, com presença, ou não, de horizonte $\mathrm{B}$ definido e decréscimo irregular do teor de $\mathrm{C}$ com a profundidade. Além disso, a produção do eucalipto é mais baixa nesses solos, o que leva ao menor aporte de resíduos vegetais ao solo (Gatto, 2005).

Sabinópolis e Virginópolis são as regiões com maior ECS (0-100 cm), com média de 135,54 e 141,22 t ha-1, 
respectivamente (Quadro 4). A pequena variação no ECS entre as regiões (diferença de $4 \%$ ) reflete a semelhança de características climáticas e fisiográficas (Quadro 1) e do solo entre elas. Na região de Virginópolis, resultado semelhante foi obtido por Lima et al. (2006), que verificaram maior estoque de C e maior teor de $\mathrm{C}$ total acumulado em plantações de E. urophylla, com idades de 10 a 33 anos.

Considerando-se as classes de solo e regiões, o estoque de $\mathrm{C}$ orgânico no solo foi menor na região do Rio Doce (Quadro 4). Essa região é situada em relevo mais plano que o das demais, com altitude média de $290 \mathrm{~m}$, clima tropical (Aw), temperatura média anual de $25,5{ }^{\circ} \mathrm{C}$ e déficit hídrico acentuado $(300 \mathrm{~mm})$, durante os meses de inverno (Quadro 1). Nessas condições, a produtividade média do eucalipto é menor (Quadro 1) e a decomposição e a mineralização da MOS são favorecidas, refletindo, consequentemente, em menor quantidade de $\mathrm{C}$ incorporado e estocado no solo, comparativamente à das demais regiões em estudo, localizadas em maiores altitudes, de temperaturas mais amenas e déficit hídrico menos acentuado. Além disso, a massa de manta orgânica é menor, com média de 16,4 t ha-1, aos 84 meses de idade em comparação à das demais regiões (Gatto, 2005). Na região de Sabinópolis, a massa de manta orgânica acumulada sobre o solo é de $28,8 \mathrm{t} \mathrm{ha}^{-1}$, seguida por Virginópolis, Cocais e Santa Bárbara, com 20,8, 19,2 e 17,7 t ha ${ }^{-1}$, respectivamente.

O estoque de C orgânico no solo resulta, principalmente, da taxa de decomposição dos resíduos da colheita florestal que permanecem sobre a superfície do solo, da manta orgânica e das raízes, que, devido à maior concentração de substâncias recalcitrantes, dão origem a formas mais estáveis de C orgânico no solo (Silva et al., 2004; Schumacher \& Witschoreck, 2004). Assim, o plantio de espécies florestais que apresentassem maior quantidade de raízes possibilitaria a alocação de grande quantidade de C orgânico no solo, o qual permaneceria estocado por período relativamente longo no solo, em comparação com o C orgânico estocado na biomassa.

Com respeito às regiões estudadas, maior ECS, aos 84 meses de idade, foi registrado na região de Virginópolis, com 141,22 t ha-1, e o menor, na região de Rio Doce, com 80,79 t ha-1 (Quadro 4), refletindo a influência das características edafoclimáticas sobre a produção de biomassa, no aporte, acúmulo e decomposição de material orgânico no solo (Quadro 1). Os valores encontrados na região de Rio Doce são 42,3 \% menores que os da região de Virginópolis; em Cocais, Sabinópolis e Santa Bárbara, o ECS foi, respectivamente, 9,9, 4,0 e 20,1\% inferior. Na região de Rio Doce, foi verificado menor ECS na classe dos FF, com 28,59 t ha ${ }^{-1}$, porém, como o ECS dessa classe é proveniente de apenas uma avaliação (área e perfil), não é possível afirmar que o ECS, em áreas com predomínio de FF, seja efetivamente menor em relação às demais áreas com predomínio de outras classes de solo.

\section{Estoque de carbono total no sistema solo-planta}

Nas cinco regiões, em média, o EC no lenho correspondeu a $29 \%\left(64,15 \mathrm{t} \mathrm{ha}^{-1}\right)$ do ECT no sistema solo-planta; os resíduos da colheita, a $16 \%\left(34,89\right.$ t ha $\left.^{-1}\right)$; e o solo, a $55 \%\left(122,71 \mathrm{t} \mathrm{ha}^{-1}\right)$ (Quadro 5). Nessas regiões, o ECB (lenho + resíduos) médio foi de $14,15 \mathrm{t} \mathrm{ha}^{-1}$ ano $^{-1}$, correspondendo $64,8 \%$ ao lenho, $13,5 \%$ às raízes, 9,8 \% à manta orgânica, 6,9\% à casca, 3,4\% aos galhos e 1,6\% às folhas. Reis et al. (1994), empregando o método indireto de estimativa do ECB em plantações de eucalipto com produtividade média de $35 \mathrm{~m}^{3} \mathrm{ha}^{-1} \mathrm{ano}^{-1}$, aos 84 meses de idade, chegaram a valores de ECB de 10,32 t ha ${ }^{-1}$ ano $^{-1}$, sendo $65 \%$ provenientes da biomassa do tronco, $13 \%$ da copa e $22 \%$ de raízes. Acrescentaram, ainda, $20 \%$ ao valor estocado na biomassa viva, correspondente à

Quadro 5. Estoque de carbono total (ECT) e partição no sistema solo-biomassa de plantações de eucalipto, aos 84 meses de idade

\begin{tabular}{|c|c|c|c|c|c|c|}
\hline \multirow{2}{*}{ Compartimento } & \multicolumn{5}{|c|}{ Região(1) } & \multirow{2}{*}{ Média } \\
\hline & $\mathrm{CO}$ & RD & SA & SB & VI & \\
\hline & \multicolumn{6}{|c|}{$-\operatorname{ECT}\left(t h a^{-1}\right)$} \\
\hline Lenho & $\begin{array}{l}54,97 \\
(0,26)^{(2)}\end{array}$ & $\begin{array}{c}69,07 \\
(0,37)\end{array}$ & $\begin{array}{c}75,88 \\
(0,30)\end{array}$ & $\begin{array}{c}68,60 \\
(0,31)\end{array}$ & $\begin{array}{c}52,23 \\
(0,23)\end{array}$ & $\begin{array}{c}64,15 \\
(0,29)\end{array}$ \\
\hline Resíduos ${ }^{(3)}$ & $\begin{array}{c}30,55 \\
(0,14)\end{array}$ & $\begin{array}{c}36,98 \\
(0,20)\end{array}$ & $\begin{array}{l}40,19 \\
(0,16)\end{array}$ & $\begin{array}{c}36,58 \\
(0,17)\end{array}$ & $\begin{array}{c}30,17 \\
(0,13)\end{array}$ & $\begin{array}{c}34,89 \\
(0,16)\end{array}$ \\
\hline Solo $(0-100 \mathrm{~cm})$ & $\begin{array}{r}127,26 \\
(0,60)\end{array}$ & $\begin{array}{c}80,79 \\
(0,43)\end{array}$ & $\begin{array}{r}135,54 \\
(0,54)\end{array}$ & $\begin{array}{r}112,89 \\
(0,52)\end{array}$ & $\begin{array}{r}141,22 \\
(0,63)\end{array}$ & $\begin{array}{c}122,71 \\
(0,55)\end{array}$ \\
\hline Total & $\begin{array}{r}212,78 \\
(1,00)\end{array}$ & $\begin{array}{r}186,84 \\
(1,00)\end{array}$ & $\begin{array}{r}251,61 \\
(1,00)\end{array}$ & $\begin{array}{r}218,07 \\
(1,00)\end{array}$ & $\begin{array}{r}223,62 \\
(1,00)\end{array}$ & $\begin{array}{r}221,75 \\
(1,00)\end{array}$ \\
\hline
\end{tabular}

(1) CO: Cocais; RD: Rio Doce; SA: Sabinópolis; SB: Santa Bárbara; VI: Virginópolis. ${ }^{(2)}$ Partição do EC em relação ao ECT. ${ }^{(3)}$ Resíduos da colheita (casca + folhas + galhos + raízes + manta orgânica). 
produção média de matéria orgânica morta ao longo de uma rotação de sete anos, resultando no ECB de 12,38 t ha $^{-1}$ ano $^{-1}$.

O ECB médio, obtido neste trabalho (14,15 t ha ${ }^{-1}$ ano ${ }^{-1}$ ), aos 84 meses de idade, é superior aos comumente usados como referência do potencial de fixação de $\mathrm{C}$ de plantações florestais de rápido crescimento, implantadas com espécies do gênero Eucalyptus no Brasil e no mundo (IPCC, 2000, Benitez et al., 2007). Comparativamente a outros países, tradicionais produtores de madeira, localizados em regiões geográficas de clima temperado, como a Nova Zelândia, o Chile e o Canadá, o País apresenta grande potencial de contribuição ao esforço coletivo mundial para mitigação do aquecimento global, com a implantação de novas áreas com plantações florestais de rápido crescimento.

Entre as cinco regiões, o ECS, em relação ao ECT, variou de $43 \%$ na região de Rio Doce a $63 \%$, em Virginópolis. Esses valores percentuais correspondem a 80,79 e $141,22 \mathrm{t} \mathrm{ha}^{-1}$ de $\mathrm{C}$, respectivamente (Quadro 5).

Os resultados apresentados endossam a premissa de que os solos sob plantações florestais de rápido crescimento, em regiões tropicais, podem ser considerados o maior dreno para o estoque de $\mathrm{C}$ no sistema solo-planta.

\section{Relações entre ECS e características do ambiente}

A influência das características climáticas, fisiográficas e edáficas pode ser confirmada pelas correlações com o ECS (Quadro 6) e equações preditivas do ECS (Quadro 7). As correlações negativas entre os nutrientes minerais e características químicas derivadas, como $\mathrm{SB}$ e V, podem ser interpretadas de duas formas: a primeira, que solos mais férteis permitem maior produção florestal e que a análise do solo anos após o crescimento das árvores mostraria teores mais baixos em razão da imobilização dos nutrientes na biomassa, fato também descrito por Barros \& Novais (1996) e por Fabres et al. (1987) na mesma região deste estudo; a segunda, que solos mais férteis poderiam favorecer a atividade microbiana na decomposição dos resíduos vegetais.

A correlação negativa entre ECS e densidade do solo é mais facilmente entendida pela restrição que solos mais coesos oferecem ao crescimento de raízes. Neste estudo, a densidade da camada superficial foi a que significativamente se relacionou com o ECS, pois é a primeira barreira a ser vencida pelas raízes. A menor densidade radicular pode levar à menor absorção de nutrientes - especialmente em solos mais intemperizados, que são mais férteis superficialmente - e de água pelas plantas.

Quadro 6. Coeficientes de correlação (r) entre o estoque de carbono no solo e características climáticas, fisiográficas e edáficas, por camadas do solo

\begin{tabular}{|c|c|c|c|c|}
\hline \multirow{2}{*}{ Característica } & \multicolumn{4}{|c|}{ Profundidade $(\mathrm{cm})$} \\
\hline & $0-20$ & $20-40$ & $40-60$ & $60-100$ \\
\hline pH em água & $-0,16$ & $-0,37^{*}$ & $-0,27$ & $-0,61^{* *}$ \\
\hline $\mathrm{P}\left(\mathrm{mg} \mathrm{dm}^{-3}\right)$ & $-0,26$ & $-0,14$ & $-0,08$ & $-0,33$ \\
\hline $\mathrm{K}\left(\mathrm{mg} \mathrm{dm} \mathrm{m}^{-3}\right)$ & $-0,56 * *$ & $-0,58 * *$ & $-0,48^{* *}$ & $-0,55^{* *}$ \\
\hline $\mathrm{Ca}^{2+}\left(\mathrm{cmol}_{\mathrm{c}} \mathrm{dm}^{-3}\right)$ & $-0,49 * *$ & $-0,61^{* *}$ & $-0,38^{*}$ & $-0,40^{*}$ \\
\hline $\mathrm{Mg}^{2+}\left(\mathrm{cmol}_{\mathrm{c}} \mathrm{dm}^{-3}\right)$ & $-0,55^{* *}$ & $-0,69 * *$ & $-0,63^{* *}$ & $-0,54^{* *}$ \\
\hline $\mathrm{Al}^{3+}\left(\mathrm{cmol}_{\mathrm{c}} \mathrm{dm}^{-3}\right)$ & $0,34^{*}$ & 0,39 & 0,17 & $0,30 *$ \\
\hline $\mathrm{H}+\mathrm{Al}\left(\mathrm{cmol}_{\mathrm{c}} \mathrm{dm}^{-3}\right)$ & $0,70 * *$ & $0,66^{* *}$ & $0,56 * *$ & $0,47 * *$ \\
\hline $\mathrm{SB}\left(\mathrm{cmol}_{\mathrm{c}} \mathrm{dm}^{-3}\right)$ & $-0,53 * *$ & $-0,66^{* *}$ & $-0,51^{* *}$ & $-0,53^{*}$ \\
\hline $\mathrm{t}\left(\mathrm{cmol}_{\mathrm{c}} \mathrm{dm}^{-3}\right)$ & $-0,41^{*}$ & $-0,089$ & $-0,10$ & $-0,07$ \\
\hline $\mathrm{V}(\%)$ & $-0,57 * *$ & $-0,70^{* *}$ & $-0,56^{* *}$ & $-0,57 * *$ \\
\hline $\mathrm{m}(\%)$ & $0,46^{*}$ & $0,66^{* *}$ & $0,46^{*}$ & $0,42^{*}$ \\
\hline $\mathrm{CO}\left(\mathrm{g} \mathrm{kg}^{-1}\right)$ & $0,96 * *$ & $0,95^{* *}$ & $0,88^{* *}$ & $0,95^{*}$ \\
\hline $\mathrm{DS}\left(\mathrm{g} \mathrm{cm}^{-3}\right)$ & $-0,58^{* *}$ & $-0,01$ & 0,18 & 0,07 \\
\hline $\mathrm{DP}\left(\mathrm{g} \mathrm{cm}^{-3}\right)$ & 0,13 & $-0,07$ & $-0,06$ & $0,41^{*}$ \\
\hline $\mathrm{PT}\left(\mathrm{g} \mathrm{cm}^{-3}\right)$ & 0,32 & $-0,01$ & $-0,02$ & $0,44^{*}$ \\
\hline Areia (g kg-1) & $-0,27$ & $0,26^{*}$ & $0,40^{*}$ & $-0,03$ \\
\hline Silte $\left(\mathrm{g} \mathrm{kg}^{-1}\right)$ & 0,25 & $-0,28$ & $-0,39 *$ & $-0,54 * *$ \\
\hline Argila $\left(\mathrm{g} \mathrm{kg}^{-1}\right)$ & 0,14 & $-0,05$ & 0,02 & $0,37 *$ \\
\hline Prod. média aos sete anos $\left(\mathrm{m}^{3} \mathrm{ha}^{-1}\right)$ & 0,26 & 0,34 & 0,27 & 0,17 \\
\hline Temperatura média anual $\left({ }^{\circ} \mathrm{C}\right)$ & $-0,61 * *$ & $-0,40 *$ & $-0,38^{*}$ & $-0,29$ \\
\hline Precipitação pluvial média anual (mm) & $-0,12$ & 0,19 & 0,22 & 0,13 \\
\hline Déficit hídrico anual (mm) & $-0,42^{*}$ & $-0,44 * *$ & $-0,52^{* *}$ & $-0,24$ \\
\hline Altitude média (m) & $0,55^{* *}$ & $0,47 * *$ & $0,51 * *$ & 0,27 \\
\hline
\end{tabular}

**, *: significativos a 1 e $5 \%$, respectivamente. 
Quadro 7. Equações de regressão para estimativa do estoque de carbono no solo (ECS), em função de características climáticas, fisiográficas e edáficas da região centro-leste de MG

\begin{tabular}{ccc}
\hline Profundidade & Equação de regressão & $\mathbf{R}^{2}$ \\
\hline $\mathrm{cm}$ & $\mathrm{ECS}=-0,6833+0,0254^{* *}$ Altitude $+0,0299^{*}$ Argila $+7,019^{*} \mathrm{Al}^{3+}$ & 0,50 \\
$0-20$ & $\mathrm{ECS}=37,66-0,0842^{* *}$ Def. Hídrico $+9,7742^{* *} \mathrm{Al}^{3+}$ & 0,46 \\
$20-40$ & $\mathrm{ECS}=30,42-0,0661^{* *}$ Def. Hídrico $+4,9411^{*} \mathrm{Al}^{3+}$ & 0,34 \\
$40-60$ & $\mathrm{ECS}=21,05 \quad-0,0641^{*}$ Def. Hídrico $+0,0274^{* *}$ Argila $+9,4293^{*} \mathrm{Al}^{3+}$ & 0,35 \\
$60-100$ & $\mathrm{ECS}=122,73 \quad-0,3034^{* *}$ Def. Hídrico $+0,1055^{*}$ Argila & 0,30 \\
$0-100$ & &
\end{tabular}

**, *: significativos a 1 e $5 \%$, respectivamente.

Quanto a $\mathrm{Al}^{3+}$ e acidez potencial $(\mathrm{H}+\mathrm{Al})$ do solo, ambos apresentaram coeficientes de correlação positivos com ECS, praticamente, em todas as camadas (Quadro 6). Essa condição pode estar associada às baixas concentrações de $\mathrm{Ca}^{2+}$ e de $\mathrm{Mg}^{2+}$ com a redução da atividade microbiana e da decomposição e a mineralização da MOS (Zech et al., 1997), ou ser decorrente da maior absorção das bases do solo e consequente predomínio de elementos de reação ácida no complexo de troca.

$\mathrm{O}$ teor de $\mathrm{C}$ orgânico no solo é, obviamente, a variável que melhor se correlacionou com o ECS, nas quatro profundidades avaliadas (Quadro 6).

Temperaturas mais elevadas na região tropical, com chuvas sazonais, causam períodos mais ou menos extensos de déficit hídrico e submetem as plantas ao estresse hídrico, fatos que resultariam em menor produção de biomassa e acúmulo de carbono no solo (Quadro 6). Entre as características climáticas, o déficit hídrico tem sido reportado como fator ambiental limitante à obtenção de elevada produtividade para o eucalipto (Almeida \& Soares, 1997; Stape et al., 2004). Sob condições de estresse hídrico e nutricional há maior partição relativa de $\mathrm{C}$ para as raízes, alteração na arquitetura do sistema radicular, com raiz pivotante bifurcada e ocorre maior crescimento das raízes para camadas mais profundas, refletindo em aumento da superfície de aquisição de água e nutrientes (Gonçalves, 1994; Neves, 2000). Resultados semelhantes aos aqui apresentados foram encontrados por Menezes (2005), ao avaliar a produtividade de plantações de eucalipto nas regiões de Virginópolis e Rio Doce.

Altitude, déficit hídrico e teores de argila e de $\mathrm{Al}$ foram as características que melhor explicaram as variações do ECS nas várias camadas de solo (Quadro 7). A melhor predição do ECS foi conseguida para a camada de 0-20 cm de profundidade, na qual $50 \%$ das variações do ECS foram explicadas de modo significativo pela altitude e pelos teores de argila e Al. $\mathrm{O}$ aumento de altitude na região do Rio Doce coincide com solos mais intemperizados e com maior teor de argila. Nessas condições, há maior aprofundamento do sistema radicular das árvores, com maior aporte de material orgânico, e em solos mais oxídicos há maior proteção da matéria orgânica contra a atuação de microrganismos (Silva et al., 2007). Em solos mais ácidos e ricos em $\mathrm{Al}$, há menor atividade microbiana e decomposição mais lenta da matéria orgânica. O aumento do déficit hídrico contribuiu para reduzir o ECS, provavelmente, pelo menor crescimento do eucalipto e aporte de material orgânico ao solo. A capacidade preditiva dos modelos decresceu com a profundidade do solo (Quadro 7).

\section{CONCLUSÕES}

1. O estoque de carbono em plantações de eucalipto variou com as condições edafoclimáticas regionais.

2. Altitude, déficit hídrico e teores de argila e $\mathrm{Al}$ foram as características responsáveis pelas maiores variações do estoque de carbono do solo.

3. O solo representa o compartimento com maior estoque do carbono do ecossistema, com mais de metade do total. O lenho contém, em média, $29 \%$ do carbono do ecossistema.

4. As plantações de eucalipto constituem opção efetiva de captura de $\mathrm{C}$ e podem imobilizar pelo menos $50 \mathrm{t} \mathrm{ha}^{-1} \mathrm{ano}^{-1}$ de $\mathrm{CO}_{2}$ da atmosfera.

\section{LITERATURA CITADA}

ALMEIDA, A.C. \& SOARES, J.V. Análise da influência da variabilidade hidrometeorológica inter anual no crescimento de plantações de eucalipto. Salvador, Embrapa, IUFRO, 1997. p.52-61.

BARROS, N.F. \& NOVAIS, R.F. Eucalypt nutrition and fertilizer regimes in Brazil. In: ATTWILL, P.M. \& ADAMS, M.A., eds. Nutrition of eucalypts. Australia, SCIRO, 1996. p. 335-355.

BENITEZ, P.C.; MacCALLUM, I.; OBERSTEINER, M. \& YAMAGATA, Y. Global potential for carbon sequestration: Geographical distribution, country risk and policy implications. Ecol. Econ., 60:572-583, 2007. 
CELULOSE NIPO-BRASILEIRA S.A. - CENIBRA. Relatório climático anual 2004. Belo Oriente, Cenibra, 2005. 22p.

CELULOSE NIPO-BRASILEIRA S.A. - CENIBRA. Relatório do levantamento semidetalhado de solos da Cenibra: Fase 2. Belo Oriente, 2001. v.I. 101p.

CERRI, C.C.; BERNOUX, M.; CARVALHO, M.C.S.C. \& VOLKOFF, B. Primeiro inventário brasileiro de emissões antrópicas de gases de efeito estufa: Emissões e remoções de dióxido de carbono pelos solos por mudanças de uso da terra e calagem. Brasília, Ministério da Ciência e Tecnologia, 2001. 41p.

ECOAR - Instituto Ecoar para Cidadania. Efeito estufa. São Paulo, 2003. 5p.

EMPRESA BRASILEIRA DE PESQUISA AGROPECUÁRIA EMBRAPA. Centro Nacional de Pesquisa de Solos. Sistema brasileiro de classificação de solos. Rio de Janeiro, 1999. $412 p$

EMPRESA BRASILEIRA DE PESQUISA AGROPECUÁRIA . EMBRAPA. Centro Nacional de Pesquisa de Solos. Manual de métodos de análise de solo. Rio de Janeiro, 1997. 212p. (Embrapa-CNPS. Documentos, 1)

FALLOON, P.; JONES, C.D.; CERRI, C.E.; AL-ADAMAT, R.; KAMONI, P.; BHATTACHARYYA, T.; EASTER, M.; PAUSTIAN, K.; KILLIAN, K.; COLEMAN, K. \& MILNE, E. Climate change and its impact on soil and vegetation carbon storage in Kenya, Jordan, India and Brazil. Agric. Ecosyst. Environ., 122:114-124, 2007.

FABIÃO, A.; PERSSON, H.A. \& STEEN, E. Growth dynamics of superficial roots in Portuguese plantations of Eucalyptus globulus Labill, studied with a mesh bag technique. Plant Soil, 83:233-242, 1985

FABRES, A.S.; BARROS, N.F. \& NOVAIS, R.F. Produtividade e exportação de nutrientes em eucaliptos e identificação de sítios visando o manejo do solo e o manejo florestal em áreas da Cenibra. Viçosa, MG, Convênio SIF/CNB-F, 1987. 142p. (Relatório Anual/Programa, 86-87)

FONSECA, S. Propriedades físicas, químicas e microbiológicas de um Latossolo vermelho-amarelo sob eucalipto, mata natural e pastagem. Viçosa, MG, Universidade Federal de Viçosa, 1984. 78p. (Tese de Mestrado)

GATTO, A. Estoques de carbono no solo e na biomassa de plantações de eucalipto na Região Centro-Leste de Minas Gerais. Viçosa, MG, Universidade Federal de Viçosa, 2005. 159p. (Tese de Doutorado)

GONÇALVES, J.L.M. Características do sistema radicular de absorção do Eucalyptus grandis sob diferentes condições edáficas. Piracicaba, Escola Superior de Agricultura Luiz de Queiroz, 1994. 84p. (Tese de Livre Docência)

HASSINK, J.; WHITMORE, A.P. \& KUBÁT, J. Size and density fractionation of soil organic matter and the physical capacity of soils to protect organic matter. Eur. J. Agron., 7:189-199, 1997.

INTERGOVERNMENTAL PANEL ON CLIMATE CHANGE IPCC. Land use, land use change, and forestry. Cambridge, Cambridge University Press, 2000. p.5.1-5.75.
KÄTTERER, T.; FABIÃO, A.; MADEIRA, M.; RIBEIRO, C. \& STEEN, E. Fine-root dynamics, soil moisture and soil carbon content in na Eucalyptus globulus plantation under different irrigation and fertilization regimes. For. Ecol. Manag., 74:1-12, 1995.

KÖGEL-KNABNER, I.; GUGGENBERGER, G.; KLEBER, M.; KANDELER, E.; KALBITZ, K.; SCHEU, S.; EUSTERHUES, K. \& LEINWEBER, P. Organo-mineral associations in temperate soils: Integrating biology, mineralogy, and organic matter chemistry. J. Plant Nutr. Soil Sci., 171: 61-82, 2008.

KRISHNAMURTHY, L. \& AVILA, M. Agroforesteria básica. México, Red. de Formación Ambiental para América Latina y el Caribe. Programa de las Naciones Unidas para el Médio Ambiente, 1999. p.29-36.

LAL, R. Forest soils and carbon sequestration. For. Ecol. Manag., 220:242-258, 2005.

LAL, R.; KIMBLE, J. \& STEWART, B.A. World soils as a source or sink for radiatively-active gases. In: LAL, R.; KIMBLE, J.; LEVINE, E. \& STEWART, B.A., eds. Soil management and greenhouse effect. Boca Raton, CRC Lewis Publishers, 1995. p.1-7.

LEITE, F.P. Relações nutricionais e alterações de características químicas de solos da região do Vale do Rio Doce pelo cultivo do eucalipto. Viçosa, MG, Universidade Federal de Viçosa, 2001. 72p. (Tese de Doutorado)

LIMA, A.M.N.; SILVA, I.R.; NEVES, J.C.L.; NOVAIS, R.F.; BARROS, N.F.; MENDONCA, E.S.; SMYTH, T.J.; MOREIRA, M.S. \& LEITE, F.P. Soil organic carbon dynamics following afforestation of degraded pastures with eucalyptus in southeastern Brazil. For. Ecol. Manag., 235: 219-231, 2006

MACHADO, A.A. \& CONCEIÇÃO, A.R. Sistema de análise estatística para Windows. WinStat. Versão 2.0. Pelotas, Universidade Federal de Pelotas, 2003.

MADEIRA, M.V.; FABIÃO, A.; PEREIRA, J.S.; ARAÚJO, M.C. \& RIBEIRO, C. Changes in carbon stocks in Eucalyptus globulus Labill, plantations induced by different water and nutrient availability. For. Ecol. Manag., 171:75-85, 2002 .

MATUS, F.J. \& MAIRE G., C.R. Relación entre la materia orgánica del suelo, textura del suelo y tasas de mineralización de carbono y nitrógeno. Agric. Técnica, $26: 112-126,2000$

MENEZES, A.A. Produtividade da cultura do eucalipto e sua relação com a qualidade e a classe de solo. Viçosa, MG, Universidade Federal de Viçosa, 2005. 91p. (Tese de Doutorado)

MIKUTTA, R. KLEBER, M. TOM, M.S. \& JAHN, R. Stabilization of soil organic matter: Association with minerals or chemical recalcitrance? Biogeochemistry, 77:25-56, 2006

NEVES. J.C.L. Produção e partição de biomassa, aspectos nutricionais e hídricos em plantios clonais de eucalipto na região litorânea do Espírito Santo. Campos dos Goytacazes, Universidade Estadual Norte Fluminense, 2000. 191p. (Tese de Doutorado) 
PULROLNIK, K.; BARROS, N.F.; SILVA, I.R.; NOVAIS, R.F. \& BRANDANI, C.B. Estoques de carbono e nitrogênio em frações da matéria orgânica de solos sob eucalipto, pastagem e cerrado no Vale do Jequitinhonha - MG. R. Bras. Ci. Solo, 33:1125-1136, 2009.

REIS, M.G.F.; REIS, G.G.; VALENTE, O.F. \& FERNANDES, H.A.C. Sequestro e armazenamento de carbono em florestas nativas e plantadas dos Estados de Minas Gerais e Espírito Santo. In: SEMINÁRIO EMISSÃO x SEQUESTRO DE $\mathrm{CO}_{2}$, 1., Rio de Janeiro, 1994. Anais... Rio de Janeiro, Companhia Vale do Rio Doce, 1994. p.157195.

SCHUMACHER, M.V. \& WITSCHORECK, R. Inventário de carbono em povoamentos de Eucalyptus spp. nas propriedades fumageiras do sul do Brasil: "Um estudo de caso". In: SANQUETTA, C.R.; BALBINOT, R. \& ZILIOTTO, M.A.B., eds. Fixação de carbono: Atualidades, projetos e pesquisas. Curitiba, AM Impressos, 2004. p.111124.

SILVA, I.R. \& MENDONÇA, E.S. Matéria orgânica do solo. In: NOVAIS, R.F.; ALVAREZ V., V.H.; BARROS, N.F.; FONTES, R.L.F.; CANTARUTTI, R.B. \& NEVES, J.C.L. eds. Fertilidade do solo. Viçosa, MG, Sociedade Brasileira de Ciência do Solo, 2007. p.275-374.

SILVA, I.R.; NOVAIS, R.F.; BARROS, N.F. \& SILVA, E.F. Manejo de resíduos e matéria orgânica do solo em plantações de eucalipto: Uma questão estratégica para a manutenção da sustentabilidade. B. Inf. Soc. Bras. Ci. Solo, 29:10-20, 2004.
SMITH, P. Land use change and soil organic carbon dynamics. Nutr. Cycling Agroecosyst., 81:169-178, 2008.

SOCIEDADE BRASILEIRA DE SILVICULTURA - SBS. Fatos e números do Brasil Florestal. 2006. Disponível em: < www.sbs.com.br> Acesso em 11 out. de 2007.

STAPE, J.L.; BINKLEY, D. \& RYAN, M.G. Eucalyptus production and the supply, use and efficienty of the use of water, light and nitrogen across a geographic gradient in Brazil. For. Ecol. Manag., 193:17-31, 2004.

TCHIENKOUA, M. \& ZECH, W. Organic carbon and plant nutrient dynamics under three land uses in the highlands of West Camerron. Agric. Ecosyst. Environ., 104:673-679, 2004.

TURNER, J. \& LAMBERT, M. Change in organic carbon in forest plantation soils in eastern Australia. For. Ecol. Manag., 133:231-247, 2000.

WALKLEY, A. \& BLACK, I.A. An examination of the Degtjareff method for determining soil organic matter and a proposed modification of the chromic acid titration method. Soil Sci., 37:29-38, 1934.

ZECH, W.; SENESI, N.; GUGGENBERR, G.; KAISER, K.; LEHMANN, J.; MIANO, T.M.; MILTNER, A. \& SCHROTH, G. Factors controlling humification and mineralization of soil organic matter in the tropics. Geoderma, 79:69-116, 1997.

ZINN, Y.L.; RESCK, D.V.S. \& SILVA, J.E. Soil organic carbon as affected by afforestation with Eucalyptus and Pinus in the Cerrado region of Brazil. For. Ecol. Manag., 166:285294, 2002. 